\title{
Lesões foliares e de ramos de laranjeira-doce causadas pela leprose-dos-citros
}

\author{
João Paulo Rodrigues Marques ${ }^{(1)}$, Juliana de Freitas-Astúa(2), Elliot Watanabe Kitajima ${ }^{(3)}$ \\ e Beatriz Appezzato-da-Glória ${ }^{(4)}$
}

\begin{abstract}
(1)Escola Superior de Agricultura Luiz de Queiroz (Esalq), Dep. de Ciências Biológicas, Caixa Postal 9, CEP 13418-900 Piracicaba, SP. E-mail: joaopaulormarques@yahoo.com.br (2)Embrapa Mandioca e Fruticultura Tropical, Rua Embrapa, s/no, CEP 44380-000 Cruz das Almas, BA. E-mail: jfastua@centrodecitricultura.br ${ }^{(3)}$ Esalq, Dep. de Entomologia, Fitopatologia e Zoologia Agrícola. E-mail: ewkitaji@esalq.usp.br (4)Esalq, Dep. de Ciências Biológicas. E-mail: bagloria@esalq.usp.br
\end{abstract}

Resumo - O objetivo deste trabalho foi apresentar a descrição anatômica dos tecidos lesionados pelo Citrus leprosis virus do tipo citoplasmático (CiLV-C), em ramos e folhas de laranjeira-doce (Citrus sinensis (L.) Osbeck) 'Pêra', e fornecer dados para a compreensão das interações entre o vírus e a planta hospedeira. Tecidos que apresentavam lesões foram seccionados em micrótomo rotativo (5-7 $\mu \mathrm{m}$ de espessura) e, posteriormente, as lâminas foram coradas e montadas em resina sintética. Nas análises realizadas no microscópio eletrônico de varredura, as amostras, depois de fixadas, foram imersas em glicerina $30 \%$ e, em seguida, criofraturadas, desidratadas em série etílica, secadas ao ponto crítico de $\mathrm{CO}_{2}$, e cobertas com uma delgada camada de ouro. As lesões foliares se iniciaram como pontuações necróticas, envolvidas por halos cloróticos que limitam o crescimento da lesão. Nos ramos, ocorreram dois tipos de lesões com fendas. Na região da fenda, houve intensa hiperplasia do parênquima cortical e floemático, que promoveu a obliteração das células condutoras do floema. A formação de ductos gomosos traumáticos nas lesões caulinares foi descrita. As alterações verificadas no floema podem explicar porque o vírus torna-se não-sistêmico.

Termos para indexação: Citrus sinensis, Citrus leprosis virus, histopatologia, ductos gomosos traumáticos.

\section{Foliar and twigs lesions of sweet orange caused by citrus leprosis}

\begin{abstract}
The objective of this work was to present the anatomical description of tissues lesioned by Citrus leprosis virus cytoplasmatic type (CiLV-C), in leaves and twigs of 'Pêra' sweet orange (Citrus sinensis (L.) Osbeck) providing new data to understand the interactions between the virus and the plant host, in Brazil. Leprosis lesions were cut on a rotary microtome (5-7 $\mu \mathrm{m}$ thick), stained and mounted in synthetic resin. For scanning electron microscope analysis, fixed tissues were immersed in glycerin $30 \%$ and criofractured, dehydrated in a graded ethylic series, critical point drying and coated with gold. Foliar lesions began as necrotic points surrounded by a yellow halo that inhibited the lesion expansion. The twigs presented two different lesions: depressed ones and pustules with ruptures. There was hyperplasia of the cortical and phloematic parenchyma cells causing the obliteration of phloematic vessels. These histological alterations of the phloem tissue could explain why the virus does not become systemic even occasionally infecting phloem parenchyma cells. The development of gummosis traumatic ducts in twig lesions was described here.
\end{abstract}

Index terms: Citrus sinensis, Citrus leprosis virus, histopathology, traumatic gum ducts.

\section{Introdução}

A cultura de laranja representa importante fonte de divisas para o país, sendo o Brasil o maior produtor mundial dessa fruta, com destaque para o Estado de São Paulo. Contudo, a produção é limitada devido à presença de doenças, com destaque para as viroses. Entre essas viroses, a leprose-dos-citros se destaca, uma vez que gastos com acaricidas para seu controle podem atingir cifras acima de US\$ 80 milhões por ano (Rodrigues et al., 2003).

Essa doença possui etiologia viral (Kitajima et al., 1972) e tem como agente causal o Citrus leprosis virus (CiLV). Atualmente se aceita que os sintomas da leprose-de-citros podem ser causados por dois vírus distintos morfologicamente: o tipo nuclear (CiLV-N), descrito por Kitajima et al. (1972), e o tipo citoplasmático (CiLV-C) descrito em Colariccio et al. (1995). 
Os vetores da doença são ácaros tenuipalpídeos, do gênero Brevipalpus (Childers et al., 2003; Rodrigues et al., 2003). No Brasil, B. phoenicis Geijkes é a única espécie relatada como vetora da doença (Bastianel et al., 2006).

A doença caracteriza-se por produzir lesões restritas aos locais de alimentação do vetor, nas folhas, nos frutos e nos ramos infectados. A lesão foliar aparece como um conjunto de halos necróticos intercalados por halos cloróticos. Nos ramos, as lesões apresentam-se como pústulas necróticas e, nos frutos, como depressões necróticas. Quando a planta apresenta alta taxa de infecção, ocorre queda prematura dos frutos e definhamento dos ramos, que podem levar a planta à morte (Rossetti, 2001).

Pouco se sabe sobre o comportamento da planta na presença desse patógeno, ou seja, das respostas das células e dos tecidos vegetais na tentativa de isolar o vírus para que este não atinja os tecidos vasculares. As partículas virais foram observadas nas células do mesofilo, no parênquima vascular e, raramente, nas células companheiras do floema (Kitajima et al., 2003), o que, segundo esses autores, seria a explicação pela qual o CiLV é não-sistêmico.

O objetivo deste trabalho foi apresentar a descrição anatômica dos tecidos lesionados pelo CiLV-C, em ramos e folhas de laranjeira-doce, e fornecer dados para a compreensão das interações entre o vírus e a planta hospedeira.

\section{Material e Métodos}

Para inoculação do CiLV-C nas plantas de laranjeiradoce [Citrus sinensis (L.) Osbeck], cultivar Pêra, uma população do ácaro Brevipalpus phoenicis, originária de Cordeirópolis, SP, e mantida na Clínica Entomológica do Centro APTA Citros Sylvio Moreira/IAC, foi multiplicada em plantas oriundas de sementes de laranjeira-doce. Esta população avirulífera foi então transferida com pincéis de poucos pêlos para folhas destacadas de laranjeira sintomática, mantidas em placas de Petri, com algodão umedecido, por um período de 72 horas, para aquisição do vírus. Após esse período, cerca de dez ácaros, já virulíferos, foram transferidos para cada planta-teste a fim de transmitirem o vírus. Foram utilizadas dez plantas-teste.

Amostras de ramos e folhas com lesões foram coletadas dessas plantas-teste, fotografadas e fixadas em solução de Karnovsky (Karnovsky, 1965). Para melhor fixação, as amostras foram levadas a uma bomba de vácuo para a retirada do ar contido nos espaços intercelulares. Após a fixação, as amostras foram desidratadas em série etílica crescente $(10,20,30,40$, $50,60,70,80,90,100 \%, 10$ min em cada graduação alcoólica) e infiltradas com a resina glicol-metacrilato (Leica Historesin) e seccionadas de 5 a $7 \mu \mathrm{m}$ de espessura. As amostras foram coradas com azul de toluidina (Sakai, 1973), para as análises histológicas usuais; com Sudan black B (Jensen, 1962), a fim de detectar substâncias de natureza lipídica; cloreto férrico, para verificar a formação de compostos de natureza fenólica (Johansen, 1940); cloreto de zinco iodado, para detectar amido (Jensen, 1962) e vermelho de rutênio, na detecção de compostos de natureza péctica (Johansen, 1940). Depois de coradas, as lâminas histológicas foram montadas em resina sintética Entellan (Merck). As imagens foram capturadas em microscópio e processadas em computador para confecção das ilustrações.

Em análises ultra-estruturais, amostras de ramos e folhas, fixadas conforme descrito foram lavadas com tampão fosfato e colocadas em glicerina $30 \%$ por duas horas, com a finalidade de evitar a formação de cristais de gelo. A seguir, as amostras foram mergulhadas em nitrogênio líquido, fraturadas, e lavadas em água destilada. As amostras resultantes da criofratura foram desidratadas em série etílica (10, 30, 50, 70, 90 e 100\%), secadas pelo método do ponto crítico de $\mathrm{CO}_{2}$, montadas sobre suporte de alumínio e cobertas com uma delgada camada de ouro (30 a $40 \mathrm{~nm}$ ). As observações e as elétron-micrografias foram realizadas no microscópio eletrônico de varredura modelo LEO VP 435, operado a $20 \mathrm{kV}$, com as escalas impressas nas próprias elétronmicrografias.

\section{Resultados e Discussão}

Nos ramos, as lesões começaram a surgir cerca de 30 dias após a inoculação, e ainda se observaram novas lesões até cerca de 70 dias. Foram observados dois tipos principais de lesões: necróticas, que formam pústulas com fendas longitudinais na casca dos ramos (Figura $1 \mathrm{~A}$ ), e necróticas deprimidas, que podem apresentar fendas ou não (Figura $1 \mathrm{~B}$ e C). As lesões do tipo pústulas com fendas longitudinais foram, em geral, maiores que as lesões deprimidas (Figura $1 \mathrm{~A}$ ). A lesão apresentava coloração marrom-escura, e as regiões adjacentes podiam ser clorofiladas (Figura 1 B) ou não (Figura 1 C). Quando esse tipo 
de lesão coalesceu com outras do mesmo tipo, ou quando essas lesões adquiriram tamanho maior, elas acabaram por envolver toda a circunferência do ramo (Figura $1 \mathrm{C}$ ). Em uma revisão recente sobre a

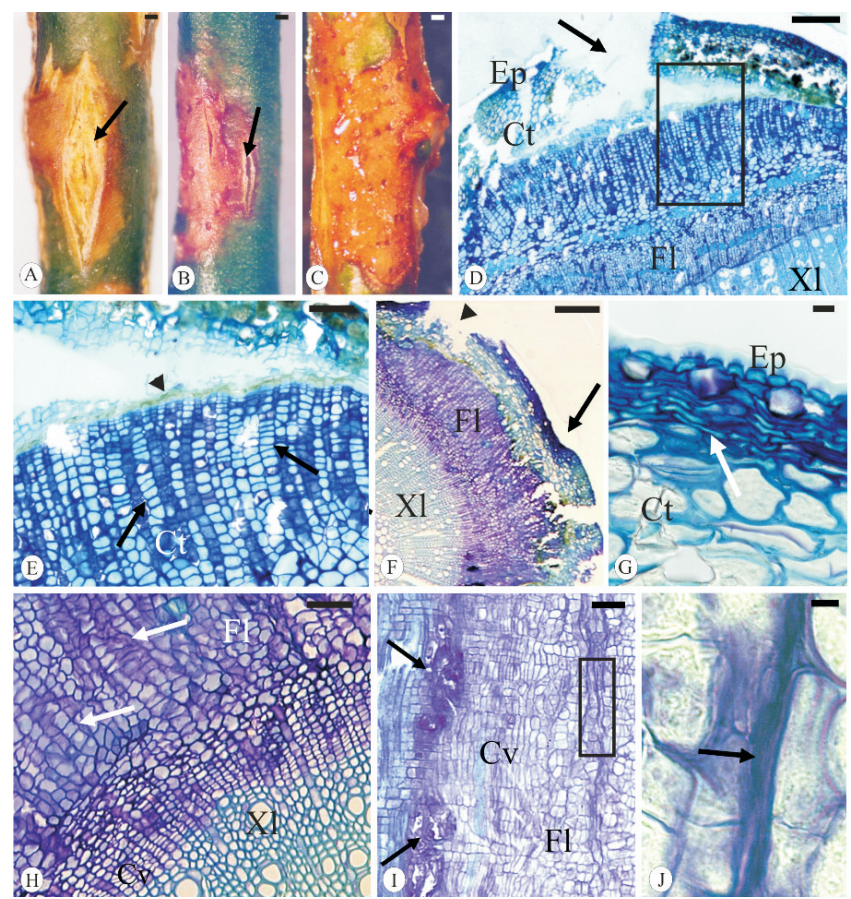

Figura 1. Aspectos morfológicos (A-C) e anatômicos (D-J) das lesões caulinares causadas pelo CiLV-C em plantas de Citrus sinensis (L.) Osbeck 'Pêra'. A: lesão necrótica do tipo pústula com fenda (seta) (barra $=2 \mathrm{~mm}$ ). B: lesão necrótica deprimida apresentando fendas (seta) (barra $=3,4 \mathrm{~mm}$ ). C: lesão necrótica deprimida (barra $=1,8 \mathrm{~mm}$ ). D: secção transversal da lesão na região da fenda. Notar o rompimento da epiderme (Ep) e do córtex $(\mathrm{Ct})($ seta) $($ barra $=100 \mu \mathrm{m})$. E: detalhe da região em destaque na foto anterior. Notar a hiperplasia das células do parênquima cortical (setas) e a formação do meristema de cicatrização (ponta de seta) $($ barra $=50 \mu \mathrm{m})$. F: visão geral da lesão necrótica deprimida. Notar a presença de fendas (ponta de seta) e de regiões deprimidas (seta) $($ barra $=200 \mu \mathrm{m}$ ). G: detalhe da região deprimida onde há colapso das células corticais (seta) (barra $=10 \mu \mathrm{m}) . \mathrm{H}$ : detalhe do tecido vascular na lesão deprimida. Notar a intensa hiperplasia (setas brancas) (barra $=50 \mu \mathrm{m}$ ). I: secção longitudinal da lesão do tipo pústula em que se observam hiperplasia do tecido floemático e a obliteração de células (destaque). Notar a presença de ductos traumáticos gomosos (setas) $($ Barra $=50 \mu \mathrm{m})$. J: detalhe de um setor do destaque na foto anterior, em que se nota o colapso das células condutoras do floema (seta) $($ barra $=10 \mu \mathrm{m}) . \mathrm{Cv}$ : câmbio vascular; F1: floema; X1: xilema. leprose-dos-citros, Bastianel et al. (2006) também relatam a coalescência de lesões em ramos jovens e a formação de lesões maiores em ramos mais velhos.

$\mathrm{Na}$ lesão do tipo pústula no ramo (Figura $1 \mathrm{~A}$ ), na região da fenda, o tecido epidérmico e a região cortical apresentaram-se necrosados (Figura 1 D). A formação da fenda resultou da lise e separação das células necrosadas devido à pressão exercida pelo aumento do número de camadas celulares no córtex subjacente. Esse aumento resultou da hiperplasia das células corticais na área da lesão (Figura 1 E) e não do acúmulo de goma nos tecidos subepidérmicos, como descrito por Bitancourt (1955), em materiais provenientes do campo. As células necrosadas do córtex apresentaram apenas compostos de natureza lipídica; os testes para fenóis e substâncias pécticas foram negativos. No entanto, sob as células corticais necrosadas, e acompanhando toda a extensão da fenda, observou-se um meristema de cicatrização, cuja camada celular mais externa apresentava conteúdo fenólico (Figura 1 E). Esse tipo de meristema é normalmente formado em áreas lesionadas e desempenha uma função de proteção a despeito da causa do ferimento (Melo-de-Pinna et al., 2002). Esses autores descreveram a formação do meristema de cicatrização e o aumento do teor de substâncias fenólicas, nas células da mina foliar de Richterago riparia, causados por uma larva de lepidóptera.

Nas lesões deprimidas (Figuras 1 B e C), a superfície do ramo apresentava-se com depressões ou com fendas (Figura $1 \mathrm{~F}$ ). As fendas eram tão profundas que expunham os tecidos vasculares (Figura $1 \mathrm{~F}$ ). Nas regiões deprimidas, células corticais subjacentes ao tecido epidérmico apresentaram colapso de suas paredes (Figura $1 \mathrm{G}$ ), devido à pressão exercida pela hiperplasia das células do parênquima floemático (Figura $1 \mathrm{H}$ ). Tanto nas regiões de fendas como nas regiões deprimidas, as células da epiderme e do córtex acumulavam substâncias lipídicas, as quais poderiam estar associadas à defesa contra patógenos, conforme discute Shah (2005). O parênquima floemático, nos dois tipos de lesões, dividiu-se periclinalmente com formação de várias camadas de células estratificadas (Figura $1 \mathrm{H}$ ), o que promoveu o colapso das células condutoras do floema (Figuras $1 \mathrm{I}$ e J) e o deslocamento das fibras pericíclicas. Nas lesões deprimidas, as paredes do parênquima floemático apresentaram sinuosidades. Segundo Roberts et al. (1997), para que haja movimento do vírus a longa distância, o vírus deve entrar nos elementos condutores 
do floema e, uma vez nesses elementos, a translocação é inteiramente passiva e determinada pelo padrão de transporte de fotoassimilados pela da planta. Portanto, as alterações no floema descritas podem restringir o CiLV-C à área lesionada e evitar a sua translocação para regiões ainda não infectadas. Isto explicaria o porquê de o vírus não se tornar sistêmico, mesmo já tendo sido observada presença esporádica de partículas virais no parênquima floemático (Bastianel et al., 2006).

Nas lesões com fendas, observou-se a formação de ductos traumáticos gomosos (Figura $2 \mathrm{~A}-\mathrm{E}$ ) semelhantes aos descritos por Gedalovich \& Fahn (1985) em ramos jovens de citros infectados com o fungo Phytophthora citrophthora. O desenvolvimento dos

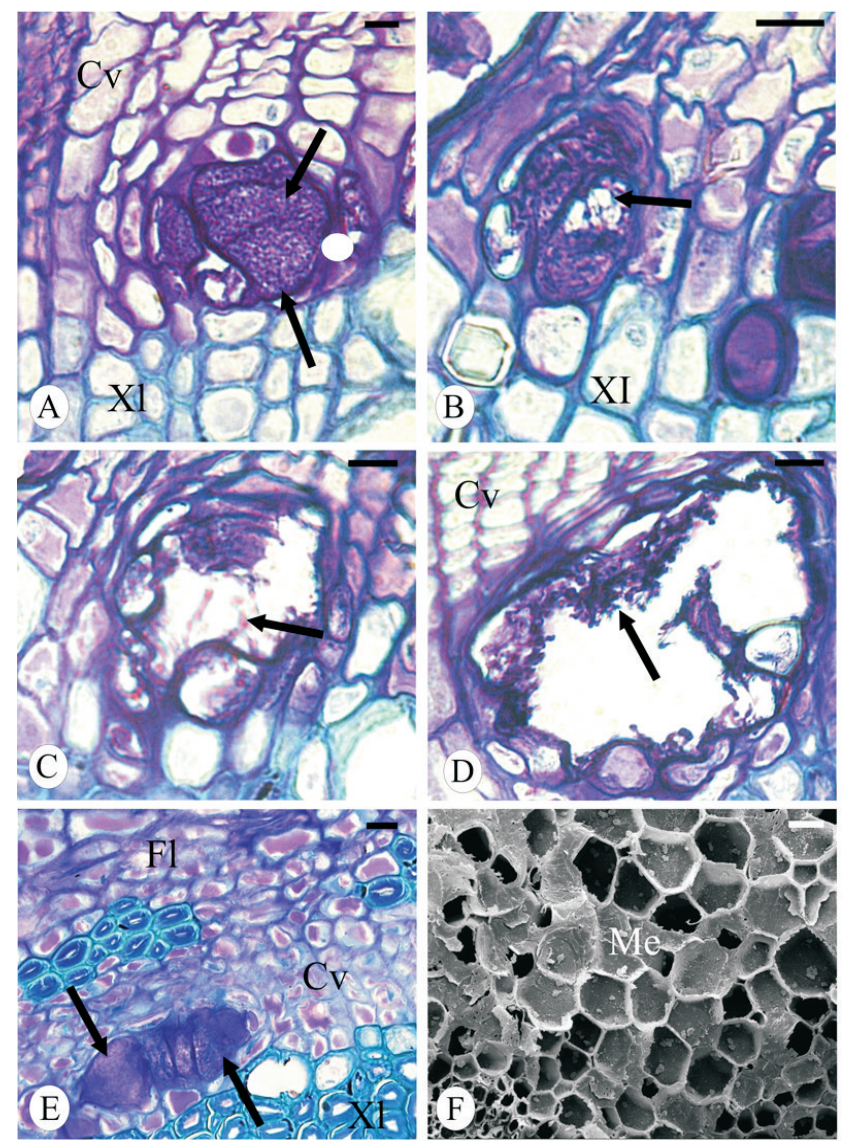

Figura 2. Secções anatômicas (A-E) e elétron-micrografia (F) dos ramos lesionados de Citrus sinensis (L.) Osbeck 'Pêra'. A-D: etapas da formação do ducto traumático gomoso (setas) (barras $\mathrm{A}-\mathrm{D}=5 \mu \mathrm{m}$ ). E: lume do ducto preenchido por compostos de natureza péctica (setas) (barra $=30 \mu \mathrm{m})$. F: células da medula (Me) com ausência de grânulos de amido (barra $=20 \mu \mathrm{m}) . \mathrm{Cv}$ : câmbio vascular; F: floema; X1: xilema. ductos em ambas as doenças começou com a alteração de células-mãe do parênquima xilemático, localizadas próximo ao câmbio (Figura $2 \mathrm{~A}$ ). No entanto, neste trabalho, verificou-se a hipertrofia das células, que passaram a secretar mucilagem, e posterior lise dessas células para formar o lume do ducto e liberar a secreção (Figura 2 B-D), enquanto Gedalovich \& Fahn (1985) verificaram a formação esquizógena do lume. As células parenquimáticas vizinhas ao lume recém-formado passaram pelo mesmo processo de hipertrofia e lise, o que levou ao aumento do lume e ao acúmulo da mucilagem no seu interior (Figura $2 \mathrm{E}$ ). A presença de mucilagem também foi verificada no interior dos vasos do xilema. Os ductos traumáticos ocorreram em toda a extensão das lesões. A produção de mucilagem nos ductos é uma resposta da planta (isolamento da área lesionada) à presença do patógeno, como sugerido por Gedalovich \& Fahn (1985). Diferentemente do tecido sadio, foi verificada ausência de grânulos de amido nas células da medula (Figura $2 \mathrm{~F}$ ), nas células do parênquima vascular e do parênquima cortical, em ambos os tipos de lesões.

Como as lesões foliares da leprose são extremamente variáveis, mesmo entre as diferentes cultivares de laranjeiradoce (Bastianel et al., 2006), na sequiência foi apresentada a descrição das lesões na laranjeira-doce 'Pêra', desde a fase inicial até a avançada (Figura $3 \mathrm{~A}-\mathrm{F}$ ).

As primeiras lesões foliares surgiram aos 30 dias após a inoculação e possuíam cerca de 1,5 mm de diâmetro. As lesões iniciaram-se como pontuações necróticas (Figura 3 A). Embora as alterações histológicas indiquem a necrose dos tecidos foliares, essas não poderiam ser consideradas como uma reação de hipersensibilidade (RH), pois a RH se manifesta em poucas horas (ou dias) e resulta em uma interação incompatível (resistência) (Kobayashi \& Vieira, 2000).

As pontuações necróticas apresentavam depressões isoladas na superfície do limbo foliar, em especial, na face abaxial, resultantes da intensa obliteração das células da epiderme e do parênquima lacunoso (Figura $3 \mathrm{G}$ ), muitas das quais apresentavam conteúdo de natureza lipídica (Figura $3 \mathrm{H}$ ). As células adjacentes às células obliteradas apresentavam núcleo volumoso e citoplasma com aspecto granular. Na lesão, era possível observar feixes vasculares necrosados (Figura 3 I e I'). As áreas necróticas deprimidas possuíam cor marrom-clara e eram circundadas por uma região clorótica (Figura 3 B), observada mais facilmente quando a lesão era examinada contra a luz. Nas áreas cloróticas, as células 
epidérmicas do parênquima clorofiliano e da bainha do feixe apresentavam-se plasmolisadas (Figura $3 \mathrm{~J}$ ). Com o aumento do halo clorótico, a lesão adquiriu diâmetro maior (cerca de 2 a $2,5 \mathrm{~mm}$ ), com formação de

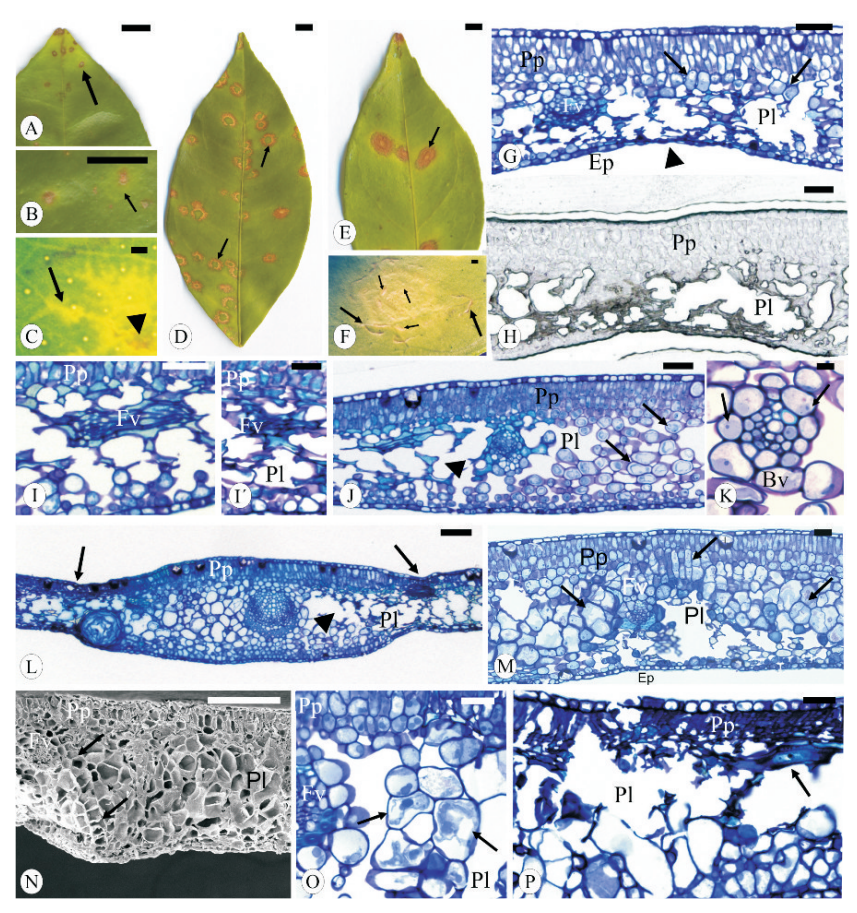

Figura 3. A-F: lesões foliares iniciais (A-C) e avançadas (D-F) causadas pelo CiLV-C em Citrus sinensis (L.) Osbeck 'Pêra'. A: lesão inicial (seta). B: lesão inicial com halo clorótico (seta). C: nervura clorótica (seta) e pontuação necrótica inicial (ponta de seta). D: lesões com o primeiro halo necrótico (setas). E: lesão avançada com intensa necrose (setas). F: primeiros halos necróticos (setas menores) e halo externo que delimita a lesão (seta maior) (barras $\mathrm{A}, \mathrm{C}-\mathrm{F}=1 \mathrm{~cm}$ e $\mathrm{B}=0,5 \mathrm{~cm}$ ). G: secção transversal da lesão inicial. Depressão no limbo (ponta de seta) e células alteradas (setas) (barra $=50 \mu \mathrm{m}$ ). $\mathrm{H}$ : compostos de natureza lipídica evidenciados pelo Sudan black B (barra $=50 \mu \mathrm{m})$. I-I': feixes vasculares colapsados $(\mathrm{Fv})$ na região da necrose. J: região entre a área necrótica (ponta de seta) e o bordo da lesão, onde ocorrem células plasmolisadas (setas). K: células da bainha vascular (Bv) com núcleo evidente (barras G-I e J $=50 \mu \mathrm{m}$; I' $=30 \mu \mathrm{m} ; \mathrm{K}=10 \mu \mathrm{m}$ ). L: regiões deprimidas (setas) onde há intensa lise celular (ponta de seta) (barra $=100 \mu \mathrm{m})$. M: células hipertrofiadas em divisão (seta) ao redor de uma região de necrose celular (barra $=50 \mu \mathrm{m}$ ). $\mathrm{N}-\mathrm{P}$ : regiões adjacentes ao halo que delimita a lesão avançada. $\mathrm{N}$ : conjunto de células em hiperplasia (setas) (barra $=100 \mu \mathrm{m})$. $\mathrm{O}$ : células do parênquima lacunoso hipertrofiadas e plasmolisadas. P: região de necrose celular próxima a um feixe vascular (seta) (barras $\mathrm{O}-\mathrm{P}=30 \mu \mathrm{m})$. Ep: Epiderme; P1: parênquima lacunoso; Pp: parênquima paliçádico. pontuações necróticas na margem da lesão, as quais coalesceram e formaram o primeiro halo necrótico (Figura 3 D). Após a formação do halo necrótico, que circundava a área clorótica inicial, outra área clorótica foi verificada por fora do referido halo, e assim sucessivamente (Figura $3 \mathrm{~F}$ ).

Nas regiões entre os halos (Figura 3 L), notam-se células com núcleo evidente na bainha do feixe vascular (Figura $3 \mathrm{~K}$ ). Nas lesões avançadas, entre as áreas das depressões, a hipertrofia celular acentuou-se (Figura $3 \mathrm{M}$ ), as células do parênquima paliçádico dividiram-se periclinalmente (Figura $3 \mathrm{~N}$ ) e algumas células hipertrofiadas estavam plasmolisadas (Figura $3 \mathrm{O}$ ). A lise celular e a concomitante necrose do parênquima paliçádico atingiram os feixes vasculares e levaram esses feixes ao colapso (Figura 3 I, I' e P), limitando a translocação do vírus para regiões ainda não infectadas (Roberts et al., 1997). As lesões em seu estágio final de maturação caracterizavam-se por apresentar um halo necrótico mais externo, que acabava por limitar o tamanho da lesão (Figura 3 E e F).

A necrose celular verificada pode limitar o deslocamento do vírus-da-leprose na folha, pois segundo Murphy \& Carr (2002), o sucesso da infecção localizada de um vírus requer a replicação e subseqüente movimento célula a célula do vírus a partir de células inicialmente inoculadas para células sadias adjacentes, via plasmodesmos.

\section{Conclusões}

1. Ramos gravemente infectados pelo Citrus leprosis virus do tipo citoplasmático (CiLV-C) definham devido ao comprometimento do transporte causado pela obliteração dos elementos de tubo crivado do floema e pela obstrução, pela mucilagem, dos elementos de vaso do xilema.

2. As alterações observadas no tecido floemático dos ramos lesionados evitam a infecção sistêmica pelo CiLV-C na planta.

3. A necrose dos feixes vasculares na folha limita o deslocamento do vírus-da-leprose.

\section{Agradecimentos}

À Fapesp, pelo apoio financeiro; ao biólogo Vandeclei Rodrigues, técnico do Centro APTA de Citricultura Sylvio Moreira, IAC, pela realização da inoculação do vírus. 


\section{Referências}

BASTIANEL, M.; FREITAS-ASTUA, J.; KITAJIMA, E.W.; MACHADO, M.A. The Citrus leprosis pathosystem. Summa Phytopathologica, v.32, p.211-220, 2006.

BITANCOURT, A.A. Estudos sobre a leprose dos Citrus I: distribuição geográfica e sintomatologia. Arquivos do Instituto Biológico, v.22, p.161-184, 1955.

CHILDERS, C.C.; FRENCH, V.; RODRIGUES, J.C.V. Brevipalpus californicus, B. obovatus, B. phoenicis, and B. lewisi (Acari: Tenuipalpidae): a review of their biology, feeding injury and economic importance. Experimental and Applied Acarology, v.30, p.5-8, 2003.

COLARICCIO, A.; LOVISOLO, A.; CHAGAS, C.M.; GALETTI, S.R.; ROSSETTI, V.E.; KITAJIMA, E.W. Mechanical transmission and ultrastructural aspects of Citrus leprosis virus. Fitopatologia Brasileira, v.20, p.208-213, 1995.

GEDALOVICH, E.; FAHN, A. The development and ultrastructure of gum ducts in Citrus plants formed as a result of brown-rot gummosis. Protoplasma, v.127, p.73-81, 1985.

JENSEN, W.A. Botanical histochemistry. San Francisco: W.H. Freeman, 1962. 408p.

JOHANSEN, D.A. Plant microtechnique. New York: McGrawHill Book Company, 1940. 523p.

KARNOVSKY, M. A formaldehyde-glutaraldehyde fixative of high osmolality for use in electron microscopy. Journal of Cell Biology, v.27, p.137-138, 1965.

KITAJIMA, E.W.; CHAGAS, C.M.; RODRIGUES, J.V.C. Brevipalpus-transmitted plant virus and virus like disease: cytopathology and some recent cases. Experimental and Applied Acarology, v.30, p.135-160, 2003.
KITAJIMA, E.W.; MULLER, G.W.; COSTA, A.S.; YUKI, W. Shot, rod-like particles associated with Citrus leprosis. Virology, v.50, p.254-258, 1972.

KOBAYASHI, A.K.; VIEIRA, L.G.E. Establishment of an in vitro system for studies on the induced resistance of cotton to Xanthomonas campestris pv. malvacearum. Pesquisa Agropecuária Brasileira, v.35, p.719-725, 2000.

MELO-DE-PINNA, G.F.A.; KRAUS, J.E.; MENEZES, N.L. de. Morphology and anatomy of leaf mine in Richterago riparia Roque (Asteraceae) in the campos rupestres of Serra do Cipó, Brazil. Brazilian Journal of Biology, v.62, p.179-185, 2002.

MURPHY, A.M.; CARR, J.P. Salicylic acid has cell-specific effects on Tobacco mosaic virus replication and cell-to-cell movement. Plant Physiology, v.128, p.552-563, 2002.

ROBERTS, A.G.; SANTA CRUZ, S.; ROBERTS, I.M.; PRIOR, D.A.M.; TURGEON, R.; OPARKA, K.J. Phloem unloading in sink leaves of Nicotiana benthamiana: comparison of a fluorescent solute with a fluorescent virus. Plant Cell, v.9, p.1381-1396, 1997.

RODRIGUES, J.V.C.; KITAJIMA, E.W.; CHILDERS, C.C.; CHAGAS, C.M. Citrus leprosis virus vectored by Brevipalpus phoenicis (Acari: Tenuipalpidae) on citrus in Brazil. Experimental and Applied Acarology, v.30, p.161-179, 2003.

ROSSETTI, V.V. Manual ilustrado de doenças dos citros. Piracicaba: Fealq-Fundecitrus, 2001. 207p.

SAKAI, W.S. Simple method for differential staining of paraffin embedded plant material using toluidine blue O. Stain Technology, v.48, p.247-249, 1973.

SHAH, J. Lipids, lipases, and lipid-modifying enzymes in plant disease resistance. Annual Review of Phytopathology, v.43, p.229-260, 2005.

Recebido em 13 de agosto de 2007 e aprovado em 30 de outubro de 2007 